\title{
RESISTANCE AND DISSONANCE IN HIGHER EDUCATION: ON DOING THINGS DIFFERENTLY
}

\author{
N. Davids* \\ e-maill: nur@sun.ac.za
}

\author{
Y. Waghid* \\ yw@sun.ac.za \\ *Department of Education Policy Studies \\ Stellenbosch University \\ Stellenbosch, South Africa
}

\section{ABSTRACT}

The historical inequalities and imbalances, so deeply embedded in the institutional structures and discourse of higher education, persist to haunt university spaces as these institutions continue to veer towards notions of transformation. While statues have been removed, buildings renamed and fees adjusted, higher education in South Africa remains a largely disparate and alienating topography - especially because of the gaping wounds left by iterative student protestations. Seemingly, the more leadership structures in higher education stonewalled student protestations, the more student resistance intensified - not only in scope, but also in violence. In this sense, we take note of Foucault's (1997) dyadic depiction of power and resistance, that is, power necessarily provokes resistance, since without resistance, there can be no power. In this article, we firstly reflect on the necessity of resistance not only in relation to power, but also as a practice that ought to be ubiquitous to higher education. Secondly, it is our contention that if higher education is to fulfil its ideological mandate of doing things differently for the sake of epistemological and public good, then it necessarily has to be underscored by dissonance.

Keywords: higher education, transformation, power, resistance, dissonance

\section{A GLANCE AT HIGHER EDUCATION IN SOUTH AFRICA}

The deep historical inequalities, inequities and disparities embedded in higher education in South Africa were always going to need a bold overhaul. This overhaul needed to (and still needs to) walk a tightrope between redressing former injustices in terms of access, resources and opportunities, and ensuring a sustainable relationship between knowledge production/development and a post-apartheid economy. The redress agenda is witnessed in the White Paper 3: A Programme for the Transformation of Higher Education (Department of 
Education (DoE) 1997), which aims to modify the higher education system into an integrated, 'single, national co-ordinated system that would ensure diversity in its organisational form and the institutional landscape, mix of institutional missions and programmes commensurate with national and regional needs in social, cultural and economic development' (DoE 1997, 2.3). The White Paper 3 (DoE 1997) was succeeded by the Higher Education Amendment Act (DoE 1998), and then the National Plan for Higher Education (DoE 2001). These education policy initiatives have been driven by a dual-purpose of firstly, separating post-apartheid higher education from its historically unequal and divisive past. And secondly, to address utilitarian demands, which have meant subscribing to a largely neo-liberalist agenda of the corporatisation and marketization of higher education. As a result, the National Plan for Higher Education (DoE 2001) identifies sixteen objectives. These include increasing student access, particularly from historically marginalised, black communities into the university sector, and enhancing students' cognitive abilities with respect to technical and professional competences that would not only ensure greater competitiveness in an ever-evolving labour market economy, but also increased participation as democratic citizens in service of the public good (DoE 2001).

Emanating from these reform measures are two sets of challenges. The first challenge relates to a recognition, which calls for the transformation and decolonisation of higher education spaces and which cannot be dislodged from South Africa's apartheid history, as confirmed by the waves of student protestations. The second challenge emanates from a realisation that the types of reform and policies, which have thus far occurred within higher education, have, as yet, not addressed past inequities and exclusions. Institutions of higher education in post-apartheid South Africa continue to be defined by wide discrepancies in terms of financial and material resources. Moreover, students, who were previously excluded due to race and ethnicity, continue to be marginalised and disadvantaged in terms of financial ability. These challenges are acknowledged by Higher Education South Africa (HESA 2014, 11) as follows:

The continued under-developed institutional capacities of historically black institutions must be emphasized; providing access to rural poor and working class black students, inadequate state support for the historically black institutions to equalize the quality of undergraduate provision compromises their ability to facilitate equity of opportunity and outcomes.

Badat (2010, 7) maintains that there continues be a problematic tension between the values and goals of higher education, and what has actually taken shape. Managing and implementing an agenda, which simultaneously redresses social equity and quality higher education, has created difficult and tense socio-political challenges (Badat 2010, 7). On the one hand, focusing 
exclusively on social equity, according to Badat (2010, 7), 'compromises the production of high quality graduates with the requisite knowledge competencies and skills, and adversely affects economic development'. On the other hand, a focus on quality or standards, 'results in equality being retarded or delayed with limited erosion of the racial and gender character of the highlevel occupational structure' (Badat 2010, 7). Higher education, therefore, is left with an unenviable situation of having to increase access to historically excluded students, without adequate funding, while also being held to particular standards of graduate attributes. Consequently, debates and discussions about the transformation in higher education is a highly contested and contestable arena. Because the transformation agenda, as Badat $(2010,7)$ argues, is embodied in paradoxes, it is to be expected that responses from students would be equally problematic and frustrated - as evident in the series of \#mustfall campaigns, which came to characterise the student protests. To Jansen $(2004,293)$, the turmoil and uncertainty in higher education in South Africa has come to resemble exactly the 'distortion, upheaval and fragmentation that marked the sector at the start of the 1990s'. At the heart of the distortion and fragmentation is a reality that the level of state funding in terms of financial aid for students who are academically eligible for admission to universities and who meet the criteria of the largely state-funded National Student Financial Aid Scheme (NSFAS) is inadequate to support all deserving students at appropriate levels for undergraduate and postgraduate study (Badat 2016, 3). Badat $(2016,4)$ explains that state is aware of the measures that are required to ensure that higher education addresses effectively equity, quality, and development problems. Moreover, continues Badat (2016, 4), the budget for higher education has increased, and funds have, indeed, been provided to address important issues and areas. What remains the problem, according to Badat $(2016,4)$ is that 'state funding has been inadequate to support universities to discharge their critical purposes of producing knowledge, cultivating high quality graduates, and engaging meaningfully with diverse communities, to play the diverse roles they must to help realize environmentally sustainable economic development, equity, social justice, and a vibrant democracy, and do all this in a way that ensures that the necessary transformations related to equity, the nature and quality of learning and teaching, research, and institutional culture also occur simultaneously within higher education'.

Du Toit $(2000,93)$ explains that the ongoing challenges and tensions created through inadequate funding, student accommodation, as well as subsistence, are exacerbated by the prospect of large debt, high drop-out rates, poor throughput rates, inadequate facilities, and largely unreconstructed epistemologies and ontologies. To Du Toit (2000, 93), one cannot ignore the fact that a number of higher education institutions continue to be immersed in a 'whiteness', which are products of the historical 'legacies of intellectual colonisation and 
racialization'. This 'whiteness' has not only perpetuated particular patterns of teaching and learning, but has left alienating and disempowering academic and institutional cultures unchanged. (Du Toit 2000, 93). For this reason, the majority of historically disadvantaged students, who have accessed historically advantaged institutions, feel displaced and disengaged not only from institutional cultures, but from their own teaching and learning experiences.

Following on the above, it becomes necessary to understand why, in spite of the immense reform and transformation in higher education, past inequalities and inequities not only persist, but are also being compounded. One way of making sense of this tension, and increasing frustration of students, is a recognition that, as elsewhere, institutions of higher education in South Africa are influenced, and continue to respond to the neoliberalist agenda of corporatisation. To Aronowitz and Giroux (2000, 333), what the corporatisation of higher education has achieved, is to annul democratic impulses by either devaluing them or absorbing such impulses within the imperatives of the marketplace. In addition, corporatisation has reformulated social issues as largely individual or economic considerations Aronowitz and Giroux (2000, 333). Aronowitz and Giroux (2000) contend that as corporate culture and values influence and define university life, a number of replacements occur. These include the replacement of social planning by corporate planning; management becomes a substitute for leadership; and the private domain of individual achievement replaces the discourse of public politics and social responsibility (Aronowitz and Giroux 2000). It would appear that, while the mechanisms for exclusion have changed from race to economics, the end result is the same: denial of access and opportunity. And because the experiences of historically disadvantaged (black) students continue to be relegated to the margins (whether in an apartheid or postapartheid society) by those in power, their responses continue to be that of resistance.

\section{THE DYADIC RELATIONSHIP BETWEEN POWER AND RESISTANCE}

The exertion of power, says Foucault $(1982,788)$, is not simply a relationship between subjects or partners - as individuals or as a collective. Rather, the exercise of power, 'is a way in which certain actions modify others' (Foucault 1982, 788). In this sense, continues Foucault (1982), the argument that power somehow exists in a diffused form, is not true. Foucault $(1982,788)$ maintains that power 'exists only when it is put into action, even if, of course, it is integrated into a disparate field of possibilities brought to bear upon permanent structures'. While power might indeed emanate from relationships of consent and consensus, power, continues Foucault (1982, 778), is neither a function of consent nor is it in itself a renunciation of freedom. In other words, the practice or exertion of power does not exist in a binary relationship to freedom. To Foucault (1982, 789), a relationship of power is defined as a 'mode of action which does not 
act directly and immediately on others. Instead, it acts upon their actions: an action upon an action, on existing actions or on those which may arise in the present or the future'.

While power might be opposed by passivity or resistance, Foucault $(1982,789)$ explains that a power relationship can only be articulated on the basis of two elements which are each indispensable if it is really to be a power relationship: "that "the other" (the one over whom power is exercised) be thoroughly recognized and maintained to the very end as a person who acts; and that, faced with a relationship of power, a whole field of responses, reactions, results, and possible inventions may open up’. To this end, Foucault $(1982,781)$ is less concerned with 'such or such' an institution of power, or group or elite or class, and is more interested in a ‘technique, a form of power'. He explains as follows:

This form of power applies itself to immediate everyday life which categorizes the individual, marks him [her] by his [her] own individuality, attaches him [her] to his [her] own identity, imposes a law of truth on him [her] which he [she] must recognize and which others have to recognize in him [her]. It is a form of power which makes individuals subjects. There are two meanings of the word 'subject': subject to someone else by control and dependence; and tied to his [her] own identity by a conscience or self-knowledge. Both meanings suggest a form of power which subjugates and makes subject to (Foucault 1982, 781).

Power, continues Foucault $(1998,63)$, ‘is everywhere' and 'comes from everywhere', making it a 'regime of truth' that infiltrates and diffuses society, which, in turn, makes power a major source of discipline and compliance. He also believes in the possibilities of action and resistance. As a 'regime of truth' (Foucault 1998, 63), higher education seemingly embodies not only knowledge production, but also a pathway out of poverty, and hence autonomy. The power constituted within higher education therefore stems from what it stands to offer, to whom it will make this offer, and whether this offer will indeed be sustainable. In this regard, students might be offered acceptance, thereby including them in the echelons of university halls, but this acceptance is a precarious one, as the strings of financial constraints and social immobility begin to tug them away from the centre of opportunity, and back towards to the periphery of marginalisation. When students resist to succumbing to the periphery, they are not only attempting to lay claim to what ought to be their rightful place to access and opportunity, but they are also laying claim to their rightful place and power to act autonomously and freely.

In order for power relationships to emerge, explains Foucault $(1997,292)$, there 'must be at least a certain degree of freedom on both sides'. On the one hand, higher education has the power to include or not to include students. Simultaneously, higher education has the power to exclude students, even after they have been included. On the other hand, students have the power to apply for inclusion as well as the power to resist when higher education attempts to 
exclude them. For Foucault (1980, 97), 'forms of resistance against different forms of power' imply that power happens within the freedom of the individual who resists what he or she encounters. Higher education, therefore, cannot simply assume that students will succumb to its hegemonic practices. Such an assumption belies the autonomy and freedom of students to act in relation to their own subjective experiences. In this sense, students are equipped, and have the power to think critically about the society in which they find themselves, they have the intelligence to make navigate and understand the 'regime of truth' of higher education, for example, and they also have the power and/or freedom to contest or resist this 'regime of truth' (Foucault 1998, 63). They therefore have the power to resist the expected conduct and compliance that higher education might expect of them. In power relationships, says Foucault (1997, 292), 'there is necessarily the possibility of resistance because if there were no possibility of resistance (of violent resistance, flight, deception, strategies capable of reversing the situation), there would be no power relations at all'. Power is dyadic in the sense that power functions when people act in multi-directional relationships, and power operates in ongoing confrontations and contestations towards change as it affects the ways in which people interact in the context of both domination and/or exclusion (Foucault 1998). Put differently, power and resistance or opposition are relational. In this respect, explains Foucault (1991, 75), resistance to power is about 'detaching the power of truth from the forms of hegemony, social, economic, and cultural, within which it operates at the present time'.

Following on the above, Foucault (1998) considers struggle or resistance as embedded within power relationships to be resistance relationships. Resistance, states Foucault $(1998,95)$, is what eludes power, and power targets resistance as its adversary. As such, forms and articulations of resistance present a perpetual source of provocation, so that complicity and complacency remain at bay. Pickett $(1996,459)$ explains that from Foucault's (1998) perspective, power is only accepted to the extent that it is hidden. This means, states Pickett (1996, 459), that unless power is relatively invisible, it (power) will provoke resistance by what it has produced. If power is to minimise resistances, maintains Pickett $(1996,459)$, then it must seek to individualise and divide the forces of the institutions it creates. For Foucault $(1980,97)$, 'forms of resistance against different forms of power', or agonism implies that power happens within the freedom of the individual who resists what he or she encounters. Stated differently, if the self does not wish to succumb to power and wishes to care for the self, then that agonism against power is in itself an expression of freedom.

In this regard, Pickett (1996, 461) asserts that having knowledge of the functioning of power is to be constructed with the goal of fostering and rendering the practice of resistance more effectively. In other words, if an individual has a better sense of the workings and 
relationships of power, he or she is better equipped to struggle or incite against it, thereby perpetually shifting towards governmentality. According to Pickett (1996, 447), Foucault dismisses imposing limits upon resistance - implying that resistance to power can neither be constrained, not contained. Foucault's (1998) resistance is ultimately wedged between two unacceptable positions: 'either place restrictions upon resistance and remain trapped in modern power, or celebrate any form of resistance and thereby sanction the worst forms of engagement'. Moreover, continues Pickett (1996, 461), if resistance is worthwhile, as Foucault (1980) clearly believes it is, then the conditions which make struggle possible should be fostered. As such, agonism as struggle and mutual incitement is necessary for the conditions that will cultivate human flourishing, since an individual will only struggle against something or another if he or she cares enough to do so.

\section{DISSONANCE AS A NEED FOR DOING THINGS DIFFERENTLY}

Throughout Foucault's writings on power relationships, he consistently reminds us of the importance of individuals and groups to contest and resist domination and exercise freedom in order to pursue their pedagogical interests. Foucault, explains Ryan (2009, 67), gives attention to how individuals might liberate themselves from the governance of social configurations, which are legitimised through 'regimes of truth' (Foucault 1998, 63). In a Foucauldian way, continues Ryan (2009, 67), freedom is neither a singular ideal, nor an achievable state - that is, freedom is not necessarily realisable. Rather, what freedom implies is a practice of constantly being cognisant and alert to the various ways in which 'regimes of truth' govern the lives of individuals and groups. Stated differently, the practice of freedom is given shape in the individual's capacity and willingness to untie and challenge the constraints and restrictions of governance. This practice, argues Ryan (2009, 67), is liberating 'in that the governance of behavioural norms and discursive rules are often hidden by their familiarity and our dependence upon them in our day to day coping. Thus, exposing them as inessential is the first step in reevaluating and loosening these norms and rules'.

In his argument for dissonance, Foucault (1983) ruptures a universalist notion of reason in human thought processes, that is, striving towards a need to adopt a de-centred conception of lived experiences. In this sense, an individual does not have to be only this or that, but can adopt any or multiple identities, referring to Foucault's $(1983,237)$ 'many ways of being'. Foucault $(1983,237)$ contends, 'From the idea that the self is not given to us, I think that there is only one practical consequence: we have to create ourselves as a work of art', implying to link the self to creativity and not to authenticity. Commensurate with Foucault's (1983) seminal thoughts on dissonance, we shall accentuate at least three aspects that could have a reasonable 
bearing on higher education discourse, more specifically, teaching and learning. For this section, we focus on our teaching with Postgraduate Certificate in Education students, in particular, how they respond to the notion of dissonance in pedagogic relationships. We examine how students respond in three ways: firstly, in relation to dissonance as 'a sudden upheaval of thought' whereby control and judgment are suspended (discomfort); secondly, about the freedom to reflect and oppose domination (criticism); and thirdly, about seeing things never before thought of (scepticism) (Foucault 1983).

Firstly, dissonance as a 'sudden upheaval of thought' can be used in pedagogic relationships with students when university teachers contrive to evoke students' responses in relation to pedagogic moments in which the former (that is, the teachers) relinquish control of a classroom. The idea of sudden upheavals speaks to both teachers and students being open to the unexpected and being prepared to have particular views or understandings disrupted. Teachers and students alike might think that they have a clear and tangible idea about this topic or that, or how a subject should be taught. But what the possibility of sudden upheavals offers, is an openness and willingness for teaching and learning to be brought into discomfort and uncertainty. In this regard, a teacher suspends his or her premature judgment about a societal occurrence and simultaneously also constrains his or her conclusive judgment about the matter. In other words, a pedagogy of discomfort is implemented when students are provoked to speak their minds yet they remain wary of offending others in a pedagogic relationship.

For instance, on the issue of whether colonialism had been advantageous for modern society, some students were challenged to think beyond the mundane and to come up with understandings that are neither convincing nor conclusive. So, some students who averred that colonialism was good for society were challenged to rethink their premature judgment without also proffering a final judgment on the matter, as new ideas would always put a new spin on a matter. In this sense, they were encouraged to suspend their initial preconceived ideas and understandings of why they thought colonialism was advantageous for a society. And, instead they were invited to consider colonialism from the perspective of those to whom colonialism might not have been advantageous. To expect students to suspend their premature judgments on any matter is not a straightforward exercise, since these judgments are deeply embedded in their own particular lived experiences. The point of the exercise had less to do with changing particular worldviews than it had to do with students being willing to think about matters anew and being willing to have their views challenged. Of course, the claim can be made that such a suspension of judgment could constrain students' speech whereby they take up a particular stand. However, the point of view that they eventually internalise in the light of more insightful thoughts could be more durable instead of haphazardly reaching finality about a matter. In any 
case, reaching finality about a matter would oppose any thought that might be more open and convincing than previously held ones. In this way, a pedagogy of discomfort is aimed at students reaching out for meanings that are persuasive without inhibiting responses that could be otherwise. In this way, learning would be continuously based on an acceptance of judgments that are neither premature nor conclusive. In any case, such judgments that are irrefutable would mark the end of learning as learning in itself would be constrained.

Secondly, students in our class are constantly encouraged to reflect freely and to oppose forms of domination constantly. This implies that even we as university teachers ought to be challenged if students found that our views are presented too dogmatically. For instance, one of us was justifiably challenged by a student when it was claimed that dissonance in teaching is not feasible for implementation with younger learners. However, if younger learners are not urged to reflect freely and to oppose even teacher dominance, such a situation would invariably inhibit student responses in pedagogic relationships. In this way, such a pedagogic relationship would no longer be an encounter, as in an encounter, the self-understandings of both learners and teachers are invoked. In any case, the earlier young children are encouraged to think about the world around them, the better placed they would be to speak out about this world, and especially the world of higher education. Inasmuch as we encounter a number of students who are willing to challenge us (as teachers) on our views, we are deeply aware and concerned about the high number of silent voices in our classroom. Too many students remain quiet in the midst of discussions and debates where their voices are most needed and valuable, especially in relation to a topic such as colonialism, for example. Of course, we recognise that these silences could, in fact, be attributed to colonialism, since the marginalisation implemented through colonialism, also ensured the muting of people's voices. When using dissonance in pedagogic encounters, students ought to see things differently. This means they should be encouraged to reflect deeply to the extent that they come up with thoughts not held or thought of before. For instance, some students expressed the view that colonialism cannot be considered a legitimate reason for human progress. Even if progress had been made, one cannot weigh these advantages without considering the contributions masses of people, especially indigenous communities, have made to the advancement of a society. Not only did indigenous people not gain from colonialism, but the alienating effect of colonialism has ensured that their contributions have been dismissed. The latter view, immediately addresses the contention that change should only be associated with the capacity of the coloniser to do so at the expense of the then excluded capacities of indigenous communities.

Thirdly, Foucault's scepticism about human thought and practice is confirmed by his insistence to see 'truths' 'from the back of your mind' (Foucault 1994, 447). In other words, 
Foucault $(1994,447)$ avers that scepticism 'allows you to see again something you had never completely lost sight of'. By implication, for Foucault, pedagogical relationships should be understood and practiced with what is nearby, yet having a distant view of such human actions. To be nearby something means that one has not abandoned that thought in its entirety and that one remains attached to a thought one has 'never before thought out' (Foucault 1994, 448). To be distant from a thought implies some detachment from a thought, which allows one 'to see again' something differently - a 'breaking-free' from an old thought that no longer surprises one (Foucault 1994, 446). By implication, assessment practices should be considered human action to which one remains attached with the possibility that one could simultaneously be detached from such action. According to Marginson (1993, 251), scepticism in education means using the process of learning for the purpose of conscious self-questioning and selfdevelopment. Marginson (1993, 251) continues by saying that Foucault 'distinguishes between knowledge that constitutes information (connaissance) and knowledge where the knowing subject - the student or researcher - uses the process of acquiring that knowledge for a process of self-transformation (savoir)'. This self-transformation, according to Foucault $(1991,69)$, is linked to the construction of what is known, that is the 'known object'. While the acquisition of connaissance is relatively easy to measure (Marginson 1993, 251), the acquisition of savoir is not. 'Self-transformation has unpredictable lifelong effects which cannot be subjected to competency measurement. Necessarily, they are diffuse and indirect. But these forms of knowledge are often the most important effects of education’ (Marginson 1993, 251).

In the main, a pedagogy of dissonance along the lines of discomfort, criticism and scepticism has the capacity to engender opportunities for pedagogic encounters to undergo plausible change. In this way, a significant aspect of higher education discourse, that is, teaching and learning through dissonance, can contribute towards actuating unwavering change and towards doing things differently. Our concerns about the increasing numbers of student protestations are not that these protestations are occurring. Indeed, as we have argued for in this article, protestations as forms of resistance are constitutive of any enactments of power, as we encounter in higher education. Here we are reminded of Ludwig Wittgenstein's parable of 'something is in the pictured pot' (Cavell 1979, 338). If one were to describe what is wrong with the aforementioned assertion, such as to describe the 'emptiness' of the assertion in the sense that a picture of a boiling pot of water does not actually have boiling water in it. Rather, it remains an image of boiling water in a pot. If there were boiling water in the pictured pot it should have the potential to transfer heat to a human's hand on touching it. So, Wittgenstein (Cavell 1979, 338) is right when he avers that there is a momentary madness in the assertion that the pictured pot actually contains boiling water. Simultaneously, those looking at the 
pictured pot cannot deny that something is in the pot, that is, boiling water. When one observes an image with a pot filled with boiling water yet have accepted that something is simultaneously in and also not in the pictured pot, then one experiences a moment of scepticism (Cavell 1979, 338). Likewise, our concerns centre on the reality that student protestations follow the same patterns and invariably end in questionable displays of violence - thereby provoking the same responses of condemnation from those in power within higher education.

The articulation of dissonance requires not only an upheaval of thought in terms of the mechanics and processes of higher education. Dissonance also requires an upheaval of thought in terms of how students locate themselves and express their resistance. In this sense, if the intention of resistance to higher education is to ensure that ongoing practices of marginalisation are erased, and that the public university addresses the needs of all public and not only those with economic capital, then students have to be as willing to do things differently. This might mean, embarking on actions of dissent, without necessarily invoking violence, that is, in much the same way one recognises boiling water in a pictured pot without accepting it as actually boiling water. It might also mean engaging in practices of dissonance whereby the acceptance of disagreement is understood as a necessary part of the pedagogical arena of higher education, so that upheaval of thought becomes a part of the deliberative process, rather than an outcome.

\section{REFERENCES}

Aronowitz, S. and H. A. Giroux. 2000. The corporate university and the politics of education. The Educational Forum 64: 332-339.

Badat, S. 2010. The challenges of transformation in higher education and training institutions in South Africa. Paper commissioned by the Development Bank of Southern Africa. https://www.ru.ac.za/.../The\%20Challenges\%20of\%20Transformation\%20in\%20High (Accessed 13 June 2016).

Badat, S. 2016. Deciphering the meanings, and explaining the South African higher education student protests of 2015-16. wiser.wits.ac.za/.../Saleem\%20Badat\%20\%20Deciphering\%20the\%20 Meanings,\%20a... (Accessed 15 June 2016).

Cavell, S. 1979. The claim of reason: Wittgenstein, skepticism, morality, and tragedy. Oxford: Clarendon Press.

Department of Education. 1997. Education White Paper No. 3: A Programme on the Transformation of Higher Education. Pretoria: Government Printers.

Department of Education. 1998. Higher Education Amendment Act. Pretoria: Government Printers.

Department of Education. 2001. National Plan for Higher Education. Pretoria: Government Printers.

DoE, see Department of Education

Du Toit, A. 2000. Critic and citizen: The intellectual, transformation and academic freedom. Pretexts: Literary and Cultural Studies 9(1): 91-104.

Foucault, M. 1977. The political function of the intellectual. Radical Philosophy 17(13): 126-33.

Foucault, M. 1980. Power and strategies. In Power/Knowledge, ed. C. Gordon, 134-145. New York: Pantheon. 
Foucault, M. 1982. The subject and power. Critical Inquiry 8(4): 777-795.

Foucault, M. 1983. M. Foucault: Beyond structuralism and hermeneutics. $2^{\text {nd }}$ Edition. Edited by H. Dreyfus and P. Rabinow. Chicago: University of Chicago Press.

Foucault, M. 1991. Discipline and punish: The birth of a prison. London: Penguin.

Foucault, M. 1994. Power: The essential Works 3. Edited by J. D. Faubion. London: Penguin Press.

Foucault, M. 1997. Ethics: Subjectivity and truth. Edited by P. Rabinow, translated by R. Hurley et al. London: Allen Lane, Penguin Press.

Foucault, M. 1998. The history of sexuality: The will to knowledge. London: Penguin.

HESA, see Higher Education South Africa.

Higher Education South Africa. 2014. South African higher education in the $20^{\text {th }}$ year of democracy: Context, achievements and key challenges. HESA presentation to the Portfolio Committee on Higher Education and Training in Parliament, 5 March, Cape Town. http://www.hesa.org.za/hesapresentation-portfolio-committee-higher-education-and-training (Accessed 18 September 2015).

Jansen, J. 2004. Changes and continuities in South Africa's higher education system, 1994 to 2004. In Changing class: Education and social change in post-apartheid South Africa, ed. L. Chisholm, first-last page. Pretoria: Human Science Research Council Press.

Marginson, S. 1993. Education and Public Policy in Australia. Cambridge: Cambridge University Press.

Pickett, B. L. 1996. Foucault and the politics of resistance. Polity 28(4): 445-66.

Ryan, P. T. 2009. Foucault's archeology: Metaphysics or pragmatics? https://cola.unh.edu/sites/ cola.unh.edu/files/student.../5_Foucualts_Archeology.pdf (Accessed 2 June 2016). 